\title{
Vitamin D receptor alleles predict growth and bone density in girls
}

Robert Vines Growth Research Centre, New Children's Hospital, PO Box 3515, Parramatta, NSW 2145, Australia C Tao

$\mathrm{T} \mathrm{Yu}$

S Garnett

J Briody

$\mathrm{H}$ Woodhead

C T Cowell

Centre for Kidney

Research, New Children's Hospital J Knight

Correspondence to: Dr Cowell.

Chang Tao, Tony Yu, Sarah Garnett, Julie Briody, John Knight, Helen Woodhead, Christopher T Cowell

\begin{abstract}
Objectives-Polymorphism of the vitamin $D$ receptor (VDR), collagen $\alpha$ I type I (Col I $\alpha I)$, and oestrogen receptor (ER) genes have been shown to account for some of the heritability of bone mineral density (BMD) in adults. This study examined this relation in prepubertal children.

Methods and subjects-The relation between genotypes of VDR gene (Taq I, Bsm I, Fok I), Col I $\alpha$ I gene (Msc I), and ER gene (Pvu II) with areal BMD, volumetric BMD, and growth were examined in 114 (68 girls) healthy 7 year old, white children.

Results-The genotype of the VDR gene (Taq I) correlated with lumbar spine (L1-4) volumetric BMD in girls only, but at no other bone sites. In girls, VDR genotype affected areal BMD at all sites. After adjusting for height and weight, however, this effect was explained completely by the independent effect of the VDR genotype on growth. Girls with genotype TT, were $3.9 \mathrm{~kg}$ heavier and $4.1 \mathrm{~cm}$ taller than those with $\mathrm{tt}$, but this relation was not present at birth. No relation was found between genotypes of the VDR gene (Fok I), Col I $\alpha I$ gene (Msc I), or ER gene (Pvu II) and BMD or growth variables.

Conclusions-In prepubertal girls, VDR alleles contribute to lumbar spine volumetric BMD variance, but the areal BMD effect reflects the relation between areal BMD and growth. VDR alleles might affect postnatal growth regulation. (Arch Dis Child 1998;79:488-494)
\end{abstract}

Keywords: vitamin D receptor alleles; volumetric bone mineral density; prepubertal children; growth

Twin and family studies suggest that up to $75 \%$ of the variance in bone mineral density (BMD) is determined genetically and several candidate genes have been identified that might be involved in this process. ${ }^{1}$ Polymorphisms of the vitamin $\mathrm{D}$ receptor (VDR) gene causing differences in bone density between the homozygous haplotypes, were first described by Morrison et al in twin studies in an older female population. ${ }^{2}$ Subsequently, over 50 studies have been reported, examining the relation between BMD and VDR genotypes at the polymorphism (Apa I, Bsm I, and Taq I) sites at intron 8/exon 9 and the Fok I site at exon $2 .{ }^{3}$ Variable effects have been reported: from no difference in BMD being attributable to the VDR alleles to a difference of $\sim 10 \%$ between the homozygous alleles. A meta-analysis of 16 published papers by Cooper and Umbach confirmed a small effect of VDR alleles of 2-3\% at the hip and lumbar spine, and less at the wrist. ${ }^{4}$ Cooper and other researchers suggested that the effect of the VDR allele might be more apparent in younger populations. ${ }^{4}$

Similarly, the effect of the VDR alleles on BMD in children has been reported to be variable, with no relation being demonstrated in 273 boys and girls, aged $8-16$ years, using an areal density technique. ${ }^{5}$ However, a significant effect was found at the spine and femoral shaft in 100 prepubertal Mexican-American girls when quantitative computer tomography, a volumetric technique, was used to assess BMD. ${ }^{6}$ Volumetric density in prepubertal children is independent of age at sites other than the lumbar spine using either quantitative computer tomography ${ }^{6}$ or dual energy $x$ ray absorptiometry, ${ }^{7}$ whereas areal BMD is age and weight dependent in children and teenagers, ${ }^{8}$ but inversely related to age in adults.

Most studies, when examining the relation between the VDR alleles (Apa I, Bsm I, and Taq I sites) and areal BMD have not determined whether the allele has an effect on growth variables. Keen et al noted an effect of VDR alleles on weight at age 1 year. ${ }^{9}$ Using the Taq I restriction enzyme, those with the tt allele, the allele shown to be associated with lower bone density in adults, were significantly heavier $(10.04 v 9.34 \mathrm{~kg})$ than those with the TT allele. In contrast, Barger-Lux et al using the Bsm I polymorphism in 32 premenopausal girls, found a significant difference between the homozygote alleles for weight, the allele associated with lower BMD being associated with the lower weight. ${ }^{10}$

Polymorphism of the oestrogen receptor (ER) gene (Pvu II), collagen $\alpha$ I type I (Col I $\alpha 1)$ gene (Msc I), and a further VDR gene (Fok I) have all been associated with differences in BMD in several adult studies, ${ }^{11}{ }^{12}$ but there are no published data in children.

Our study examines the effect of polymorphisms of VDR (Taq I, Bsm I, and Fok I), ER (Pvu II), and Col I $\alpha$ I (Msc I) on areal and volumetric BMD and growth in prepubertal boys and girls in a narrow age range, 7.0-7.8 years, to minimise the effect of age and growth on areal BMD. We hypothesised that polymorphism of VDR, ER, Col I $\alpha$ I would be related to volumetric BMD and that the effect of the VDR genotypes on BMD might be explained by the dependence of areal BMD on growth variables. 

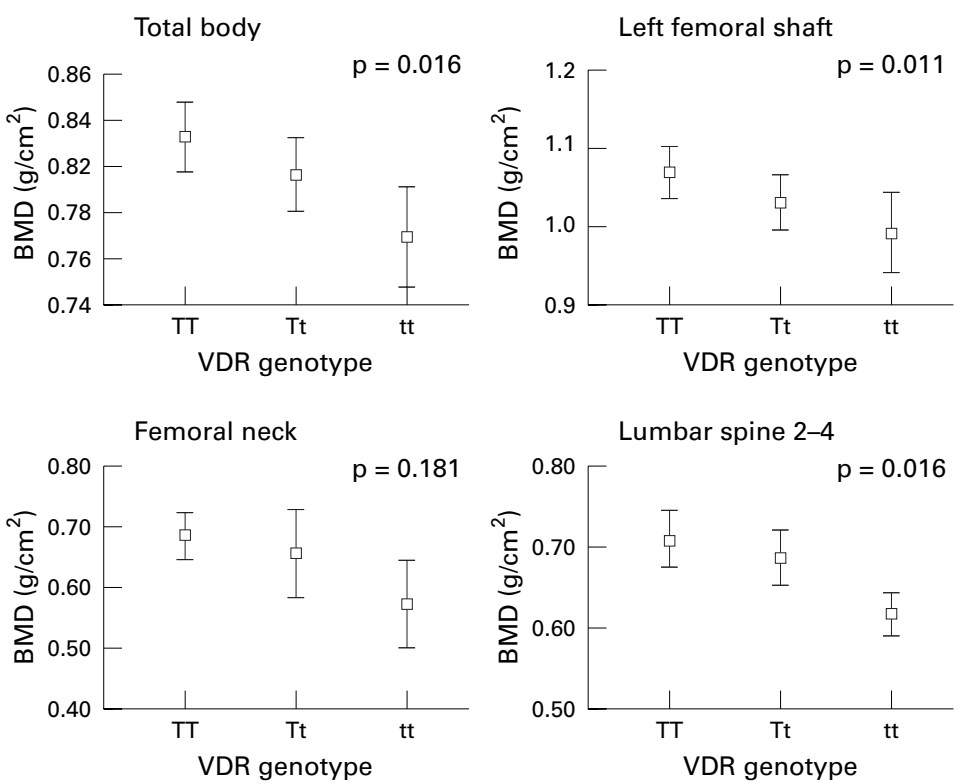

Figure 1 Areal BMD mean values (95\% CI) for the total body, femoral shaft, femoral neck, and lumbar spine in 68 girls. ANOVA analysis was used at four bony sites and $p$ values are shown in each graph. A significant difference was observed for the total body, left femoral shaft, and lumbar spine 2-4, but not the femoral neck. However, a significant difference $(p=0.003)$ was seen at the femoral neck when the Student's $t$ test was applied on TT and tt genotypes. spine volumetric BMD), 3.9\% (total body mineral content), $1.3 \%$ (soft tissue), and $3.1 \%$ (areal total body mineral density).

Multiple scans ( $\mathrm{n}=17,11$, and 17 ) performed using real bones resulted in volumetric BMD CVs of $0.6 \%, 4.7 \%$, and $1.9 \%$ for lumbar spine, left mid-femoral shaft, and femoral neck, respectively. The associated CVs of the areal $\mathrm{BMD}$ measurements were $0.4 \%, 2.1 \%$, and $0.9 \%$, respectively.

\section{ANTHROPOMETRY}

Height (Harpenden stadiometer) and weight (electronic scales) were measured on the day of the dual energy $x$ ray absorptiometry scans. Weight was measured with minimal clothing. The height, weight, and body mass index (BMI) were calculated as standard deviation scores (SDS) based on published normative data according to sex and age. ${ }^{14}$

VDR, COL I $\alpha$ I AND ER GENOTYPING

DNA was extracted from peripheral leucocytes and amplified by the polymerase chain reaction (PCR) technique with previously used primers. ${ }^{2} 3121516$ Following restriction endonuclease (Taq I) digestion of the DNA products for three hours at $65^{\circ} \mathrm{C}$, the genotype of the VDR gene was determined by fragment separation on a $2 \%$ agarose gel. Details have been described previously. ${ }^{16}$ The genotypes were classified as: TT, homozygotes, absence of the Taq I site results in two fragments of $490 \mathrm{bp}$ and $245 \mathrm{bp}$; Tt, heterozygotes exhibiting fragments of $490 \mathrm{bp}, 290 \mathrm{bp}, 245 \mathrm{bp}$, and $205 \mathrm{bp}$; tt, homozygotes, presence of the site results in three fragments of $290 \mathrm{bp}, 245 \mathrm{bp}$, and $205 \mathrm{bp}$. The polymorphism (Bsm I) of the VDR gene ${ }^{2}$ was also investigated in our study. The haplotype pattern was identical to the VDR gene polymorphism identified at the Taq I site, except in two individuals. Thus, VDR gene polymorphism (Bsm I) results have not been included in our paper. In addition, another polymorphism (Fok I) of the VDR gene $^{3}$ was analysed in our study. After amplification of DNA, the PCR products were digested by the restriction endonuclease Fok I for three hours at $37^{\circ} \mathrm{C}$, the genotype (Fok I) of the VDR gene was determined by fragment separation on a $3 \%$ agarose gel. The genotypes were classified as: FF, homozygotes, absence of the Fok I site results in one fragment of $265 \mathrm{bp}$; Ff, heterozygotes exhibiting fragments of $265 \mathrm{bp}, 196 \mathrm{bp}$, and $69 \mathrm{bp}$; ff, homozygotes, presence of the site results in two fragments of $196 \mathrm{bp}$ and $69 \mathrm{bp}^{3}$

The ER gene genotype was determined by fragment separation on a $2 \%$ agarose gel after restriction endonuclease (Pvu II) digestion of the DNA as described previously. ${ }^{15}$ The genotypes were classified as: $1.3 \mathrm{~kb}$, homozygous absence of the Pvu II site; $1.3 / 0.85 \mathrm{~kb}$, heterozygotes; and $0.85 / 0.45 \mathrm{~kb}$, homozygous presence of the Pvu II site.

The Col I $\alpha$ I gene genotype was determined after restriction endonuclease digestion with Msc I, as described previously. ${ }^{12}$ The genotypes were classified as: SS, homozygotes, absence of the Msc I site resulting in one fragment of 
Total body
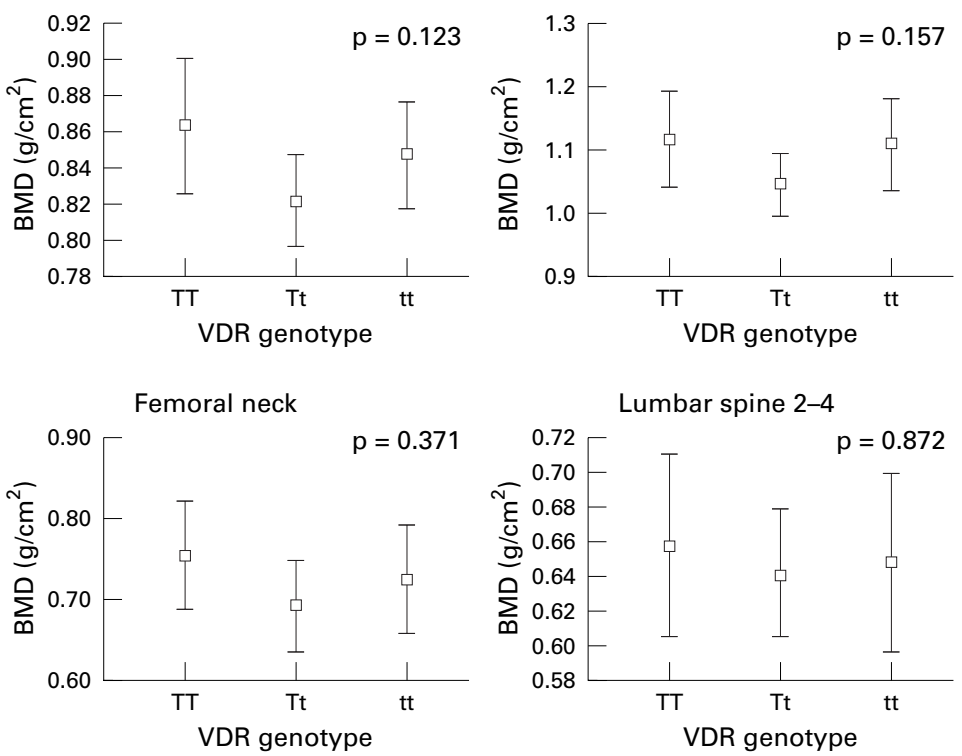

Figure 2 Areal BMD mean values (95\% CI) for the total body, femoral shaft, femoral neck and lumbar spine in 46 boys. A relatively large error bar was seen in each graph. No significant difference was shown at any of the four sites in this group.

$255 \mathrm{bp}$; Ss, heterozygotes exhibiting fragments of $255 \mathrm{bp}, 236 \mathrm{bp}$, and $19 \mathrm{bp}$; and ss, homozygotes, presence of the Msc I site results in two fragments of $236 \mathrm{bp}$ and $19 \mathrm{bp}$.

\section{STATISTICAL ANALYSIS}

Data were analysed using SPSS. ${ }^{17}$ Associations between variables were examined using linear regression models. The effect of the genotypes on subject characteristics and BMD were compared by analysis of variance (ANOVA). The differences between means were calculated after adjusting for height and weight using analysis of covariance (ANCOVA). Significance levels were set at $\mathrm{p} \leqslant 0.05$.

\section{Results}

Our study population consisted of 114 children, 68 girls and 46 boys. Their mean age was

Table 1 Mean (SE) body mass density by VDR genotype (TaqI) adjusted for height and weight

\begin{tabular}{|c|c|c|c|c|}
\hline & \multicolumn{3}{|l|}{ Genotype } & \multirow[b]{2}{*}{$p$ value } \\
\hline & $T T$ & $T t$ & $t t$ & \\
\hline \multicolumn{5}{|l|}{ Girls } \\
\hline \multicolumn{5}{|c|}{ Areal body mass density } \\
\hline $\mathrm{n}$ & 24 & 33 & 11 & \\
\hline Total body & $0.817(0.008)$ & $0.811(0.009)$ & $0.785(0.011)$ & 0.070 \\
\hline Left femoral shaft & $1.039(0.016)$ & $1.040(0.017)$ & $1.021(0.023)$ & 0.486 \\
\hline Femoral neck & $0.661(0.018)$ & $0.664(0.036)$ & $0.601(0.032)$ & 0.284 \\
\hline Lumbar 2-4 & $0.690(0.016$ & $0.685(0.165)$ & $0.638(0.011)$ & 0.038 \\
\hline \multicolumn{5}{|c|}{ Volumetric body mass density } \\
\hline Left femoral shaft & $0.717(0.015)$ & $0.710(0.013)$ & $0.706(0.019)$ & 0.791 \\
\hline Femoral neck & $0.657(0.021)$ & $0.614(0.030)$ & $0.580(0.031)$ & 0.167 \\
\hline Lumbar $1-4$ & $0.313(0.007)$ & $0.307(0.006)$ & $0.289(0.007)$ & 0.049 \\
\hline \multicolumn{5}{|l|}{ Boys } \\
\hline \multicolumn{5}{|l|}{ Areal body mass density } \\
\hline $\mathrm{n}$ & 11 & 26 & 9 & \\
\hline Total body & $0.857(0.016)$ & $0.815(0.012)$ & $0.839(0.012)$ & 0.353 \\
\hline Left femoral shaft & $1.103(0.034)$ & $1.031(0.024)$ & $1.082(0.031)$ & 0.703 \\
\hline Femoral neck & $0.751(0.029)$ & $0.683(0.027)$ & $0.700(0.028)$ & 0.206 \\
\hline Lumbar 2-4 & $0.643(0.024)$ & $0.635(0.018)$ & $0.634(0.021)$ & 0.738 \\
\hline \multicolumn{5}{|c|}{ Volumetric body mass density } \\
\hline Left femoral shaft & $0.780(0.032)$ & $0.710(0.014)$ & $0.762(0.018)$ & 0.596 \\
\hline Femoral neck & $0.733(0.030)$ & $0.664(0.017)$ & $0.663(0.029)$ & 0.081 \\
\hline Lumbar 1-4 & $0.272(0.007)$ & $0.280(0.005)$ & $0.275(0.009)$ & 0.830 \\
\hline
\end{tabular}

p value using ANCOVA test.
7.2 (range, 7.0-7.9 years), the mean height SDS was 0.41 (range, -2.14 to 4.86 ), and the mean weight SDS was 0.68 (range, -1.89 to 5.93). There were several individuals who were extremely tall and heavy and their data have been included. There were no statistical differences between boys and girls for age, weight SDS, and height SDS (data not shown). However, a significant sex difference in volumetric BMD was found at the femoral neck $(p=0.01)$ and lumbar spine $(p=0.001)$, but not at the left mid-femoral shaft.

GENOTYPES

The frequency of the VDR genotype TT was 0.59 in girls and 0.52 in boys. The frequency of the ER genotype $0.85 / 0.45 \mathrm{~kb}$ was 0.67 in girls and 0.63 in boys. The frequency of the Col I $\alpha$ I genotype SS was 0.79 in girls and 0.88 in boys. There were no sex differences in the frequencies of the VDR genotypes (Taq I) and the ER genotypes (Pvu II). Only one of the 68 girls and none of the 46 boys had the Col I $\alpha 1$ genotype ss.

AREAL BMD AND VDR GENOTYPES

Figure 1 shows the relation between VDR genotypes and areal BMD $\left(\mathrm{g} / \mathrm{cm}^{2}\right)$ for the total body, left mid-femoral shaft, femoral neck, and lumbar spine sites in girls. Using ANOVA, those with the tt genotype had significantly lower areal BMD for the total body, left mid-femoral shaft, and lumbar spine sites ( $p=0.016,0.011$, and 0.016 , respectively), but not femoral neck BMD ( $p=0.18)$. The areal BMD results for boys are shown in fig 2 . In contrast to girls, boys with the $\mathrm{Tt}$ genotype were found to have the lowest areal BMD, but the differences were not significant.

Areal BMD is known to be height and weight dependent. ${ }^{7}$ At all sites, in both sexes, areal BMD was significantly related to height and weight (data not shown). To examine further the interaction between VDR genotype and areal BMD, ANCOVA was used to adjust for the confounders height and weight. Table 1 shows the adjusted means for the genotypes calculated from the ANCOVA regression model. After adjusting for weight and height, there was no significant difference between TT and tt genotypes for areal BMD in either sex, except at the lumbar spine in girls $(p=0.038)$ (table 1).

VOL BMD AND VDR GENOTYPE

Figure 3 shows the volumetric BMD at the femoral neck and lumbar spine in girls and boys. No relations were found between left mid-femoral shaft and femoral neck volumetric BMD with VDR genotypes and the variables of height and weight in girls. However, at the lumbar spine, girls with the tt genotype had a significantly lower adjusted volumetric BMD than those with the TT genotype $(\mathrm{p}=0.049)$ (table 1). No differences were found between the adjusted volumetric BMD means for the TT and tt genotypes in the boys (table 1).

There was no effect of VDR (Fok I), ER (Pvu II), and Col I $\alpha$ I (Msc I) genotypes on areal or volumetric BMD in either sex (data not shown). 

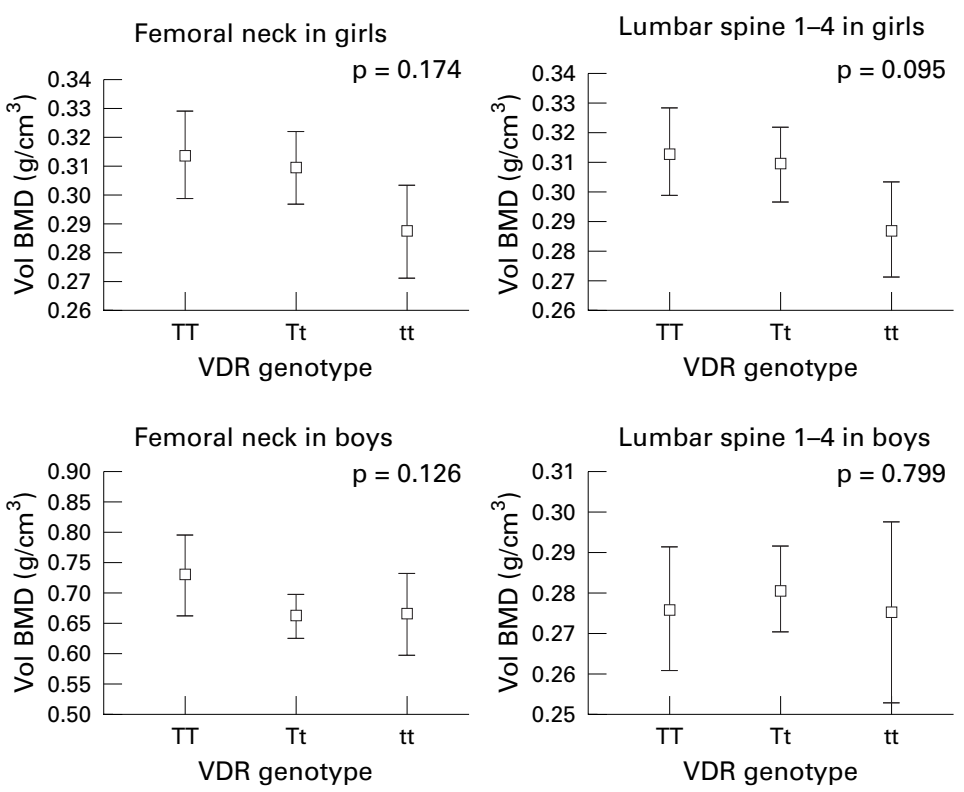

Figure 3 Volumetric BMD mean values (95\% CI) at the femoral neck and lumbar spine (1-4) in girls and boys. ANOVA testing showed no significant difference between VDR genotypes and volumetric BMD of the femoral neck and lumbar spine (1-4) in girls and boys. However, significant differences were seen at the femoral neck $(p=0.019)$ and lumbar spine 1-4 ( $p=0.027)$ when the Student's $t$ test was applied on TT and tt genotypes in girls. In contrast, the male group did not show these changes.

GROWTH AND VDR GENOTYPES

Table 2 shows height, weight, BMI, birth characteristics, and midparental height by sex and genotype of the subjects. Because most of the variability in areal and volumetric BMD in girls could be explained by height and weight, rather than by genotype, we examined the relation between genotype and growth variables. Interestingly, the results revealed that VDR genotype is involved in the regulation of body growth, with significant differences being found in girls only (table 2). Girls with the VDR genotype TT were $3.9 \mathrm{~kg} \quad(\mathrm{p}=0.03)$ heavier and $4.1 \mathrm{~cm}(\mathrm{p}=0.008)$ taller than those with the genotype tt, but no significant differences were found in boys (table 2). No significant differences were found for body composition (percentage fat and percentage lean tissue mass), birth length, weight, or mid-

Table 2 Characteristics of subjects

\begin{tabular}{|c|c|c|c|c|}
\hline & \multicolumn{3}{|l|}{ Genotype } & \multirow[b]{2}{*}{$p$ value } \\
\hline & $T T$ & $T t$ & $t t$ & \\
\hline \multicolumn{5}{|l|}{ Girls $(n=68)$} \\
\hline $\mathrm{n}$ & 24 & 33 & 11 & \\
\hline Percentage & 35.3 & 48.5 & 16.2 & \\
\hline Age (years) & $7.31(0.03)$ & $7.26(0.02)$ & $7.27(0.04)$ & 0.33 \\
\hline Weight $(\mathrm{kg})$ & $27.65(0.95)$ & $25.29(0.75)$ & $23.7(11.04)$ & 0.03 \\
\hline Height $(\mathrm{cm})$ & $126.72(1.02)$ & $123.31(0.60)$ & $122.64(1.62)$ & 0.008 \\
\hline Body mass index $\left(\mathrm{kg} / \mathrm{m}^{2}\right)$ & $17.47(0.47)$ & $16.59(0.38)$ & $15.26(0.41)$ & 0.10 \\
\hline Birth weight $(\mathrm{kg})$ & $3.43(0.10)$ & $3.22(0.79)$ & $3.28(1.29)$ & 0.27 \\
\hline Birth length (cm) & $49.71(0.42)$ & $49.07(0.39)$ & $49.04(0.85)$ & 0.51 \\
\hline Midparental height $(\mathrm{cm})$ & $163.79(1.52)$ & $164.31(0.89)$ & $163.35(1.58)$ & 0.89 \\
\hline \multicolumn{5}{|l|}{ Boys $(n=46)$} \\
\hline $\mathrm{n}$ & 11 & 26 & 9 & \\
\hline Percentage & 23.9 & 56.5 & 19.5 & \\
\hline Age (years) & $7.28(0.03)$ & $7.28(0.01)$ & $7.30(0.01)$ & 0.85 \\
\hline Weight $((\mathrm{kg})$ & $26.07(1.40)$ & $26.65(1.39)$ & $27.27(1.97)$ & 0.91 \\
\hline Height $(\mathrm{cm})$ & $125.12(2.00)$ & $125.05(1.38)$ & $127.01(2.86)$ & 0.77 \\
\hline Body mass index $\left(\mathrm{kg} / \mathrm{m}^{2}\right)$ & $16.58(1.21)$ & $16.83(1.05)$ & $16.80(1.31)$ & 0.97 \\
\hline Birth weight $(\mathrm{kg})$ & $3.78(0.15)$ & $3.52(0.10)$ & $3.28(0.13)$ & 0.10 \\
\hline Birth length (cm) & $51.22(0.91)$ & $50.36(0.43)$ & $50.00(0.89)$ & 0.52 \\
\hline Midparental height $(\mathrm{cm})$ & $177.17(2.02)$ & $175.81(1.07)$ & $171.92(6.32)$ & 0.38 \\
\hline
\end{tabular}

Values are mean (SE). p value using ANOVA test. parental height by genotype of the VDR gene (Taq I) in either sex.

\section{Discussion}

Polymorphisms of several candidate genes were investigated for associations with $\mathrm{BMD}$ in a prepubertal, white population aged 7 years. Our study found no relation between the polymorphism of the ER gene (Pvu II), the Col I $\alpha$ I gene, the VDR gene (Fok I), and BMD at three bone sites. However, we confirm the important link between VDR gene genotype (Taq I and Bsm I) and bone density seen previously in many studies in females, especially in the premenopausal age group. ${ }^{5}$ At all bone sites, there was a consistent effect of VDR genotype on areal BMD in prepubertal girls. Using a volumetric BMD technique, however, the relation with VDR genotype was only shown at the lumbar spine. This suggests that VDR might play a more a important role in trabecular bone than cortical bone in girls; similar results have been found by Ferrari et al. ${ }^{18}$

A further sex difference between volumetric BMD was found at the femoral neck and lumbar spine in our study. Previously, we had shown no sex differences at age 5-27 years at the femoral neck but a significant difference at the left mid-femoral shaft $(\mathrm{p}=0.047) .{ }^{7}$ Gilsanz et $a l,{ }^{19}$ using quantitative computer tomography, a volumetric technique, found no sex difference at the lumbar spine in the prepubertal age group. The sex difference that we observed might relate to the large sample size in a narrow age range in our study compared with the smaller sample sizes in a comparative age group in previous studies. ${ }^{719}$

Observations in twin studies suggest that $40-75 \%$ of the variance in adult BMD can be attributed to genetic influences. Conceptually, genes involved in determining an individual's bone mass could influence either bone mass accrual or bone mass resorption. Several studies have examined the effect of the VDR alleles on calcium absorption, with data suggesting that individuals with the tt genotype, which predicts low bone density, have lower calcium uptake, despite higher concentrations of circulating 1,25-hydroxyvitamin $\mathrm{D}$ and osteocalcin. ${ }^{20}{ }^{21}$ Thus, it is speculated that this VDR allele could affect bone mass accrual, which is normally completed by the late teenage years in girls, or early in the third decade in boys. ${ }^{8}$ Therefore, the optimal time to observe an effect of the VDR allele might be during the first 20 years of life.

Recently, Sainz et al have demonstrated, in a relatively homogenous Mexican-American population of prepubertal girls, an effect of the VDR allele on volumetric density at the lumbar spine and femoral shaft. ${ }^{6}$ There was an $8-10 \%$ difference between the two homozygous alleles at the lumbar spine and a $2-3 \%$ difference at the mid-femoral shaft. Our data, drawn from a narrower age range, but a less homogenous population, has shown a difference between homozygous alleles at a calculated volumetric site, the lumbar spine, in girls. Using multiple regression, we were able to estimate that the VDR genotype in girls explained $7.1 \%, 5.5 \%$, 
and $3.8 \%$ of the variation in volumetric density at lumbar spine, femoral neck, and left mid-femoral shaft sites, respectively.

An even stronger effect of the VDR alleles was demonstrated using the technique of areal density at all sites in the girls. Surprisingly, no difference was found between the homozygous VDR genotypes in boys using either the areal or volumetric technique, but the heterozygous VDR allele was lower at several sites. Because of the small number of boys in our study, a homozygous VDR allele effect might have been missed, but on inspection of our data there was not even a trend to suggest such an effect in boys.

There have been few publications examining the effect of VDR alleles in men. One study of 146 men with an age range of 20-83 years found an allelic differential effect on areal bone density. ${ }^{22}$ A further study including a small number of men $(n=29$; average age 23 years) showed an effect of the VDR allele at the femoral neck, but not the lumbar spine, when the men's data were combined with that for the women $(n=43) .^{23}$ On the other hand, two further studies that included older men could not detect any effect of the VDR allele. ${ }^{24}{ }^{25}$

Areal BMD in children and teenagers is growth dependent and any assessment of the genetic influence on areal density in children requires adjustment for growth variables. We found that after adjusting for height and weight, the VDR allele effect on areal density in girls could be explained totally by these growth variables. This led us to examine the effect of VDR genotype on growth. In fact, the difference between homozygous alleles was nearly $4 \mathrm{~kg}$ for weight and almost $5 \mathrm{~cm}$ for height. We were not able to find any significant relation between VDR genotype and either birth size or midparental height, indicating that the growth effect is likely to be a postnatal interaction between VDR genotype and the environment. The lack of effect of the VDR allele on growth in boys is difficult to reconcile.

A VDR allele effect on weight has been observed in two previous adult studies, ${ }^{9}{ }^{10}$ one a retrospective study examining weight at 1 year in individuals who are now over 60 years. ${ }^{9}$ In this study, the homozygote allele associated with low bone density was found to have a greater weight at 1 year, but not at birth, and not in boys. In contrast, a study in 32 healthy premenopausal women found that those with the VDR allele associated with low BMD were significantly lighter than those with the allele predicting higher $\mathrm{BMD} .{ }^{10}$ In our study, those girls with the allele predicting lower areal bone density (tt) were also found to be shorter and lighter (tables 1 and 2), although allele status had no growth effect in boys. In contrast, a recent study examining children at birth, 10 months, and 24 months found girls with the same polymorphism to be heavier and taller, while inversely, boys were shorter and lighter. ${ }^{26}$ In addition, the longitudinal growth analysis in full term babies observed sex related differences at birth and during infancy, suggesting some linkage between VDR gene polymor- phism and sex dependent processes, both prenatally and postnatally.

An explanation for these findings is not obvious. Several studies have examined the effect of this allele on calcium absorption and metabolism, with data indicating decreased absorption, despite higher baseline levels of 1,25-hydroxyvitamin D and osteocalcin, in the tt allele group. ${ }^{25}$ If a similar effect is present in the prepubertal age group, then this could limit calcium absorption and consequently growth. A recent study has demonstrated that giving Calcitriol, in high dosage, to postmenopausal women, resulted in higher levels of insulin-like growth factor 1 (IGF-1), the growth hormone dependent growth factor. ${ }^{27}$ Thus, it is possible that the VDR allele mediates its growth effects via IGF-1, an important regulator of growth in children. Linkage disequilibrium with a growth related gene needs to be considered. Potential candidate genes include IGF-1 and HoxC5, both of which map to the long arm of chromosome 12 , in close proximity to the VDR gene. However, there is no obvious reason why this would be sex specific.

In conclusion, a difference between the homozygote alleles of VDR was found for volumetric $\mathrm{BMD}$ in prepubertal children at the lumbar spine (L1-4) in girls. The VDR alleles were related to height and weight in girls only, and this association explained the relation between VDR genotype and areal density. Our findings suggest that VDR alleles might participate in the regulation of bone metabolism and also play a role as a postnatal growth factor in prepubertal children. Ongoing research into the mechanisms by which both these effects occur are warranted.

The authors would like to thank J Lee for her contribution in processing blood samples for the study and Dr R Fay for suggesting the studies. Our study has been supported generously by grants from the Children's Hospital Fund, Royal Alexandra Hospital for Children, Westmead, and Pharmacia and Upjohn, Sweden.

1 Ralston SH. Genetic markers of bone metabolism and bone

disease. Scand $\mathcal{F}$ Clin Lab Invest 1997;227(suppl): 114-21.
2 Morrison NA, Qi JC, Tokita A, et al. Prediction of bone Morrison NA, Qi JC, Tokita A, et al. Prediction of bone
density from vitamin D receptor alleles. Nature 1994;367: density $284-7$.

3 Harris SS, Eccleshall TR, Gross C, Dawson-Hughes B, Feldman D. The vitamin D receptor start codon polymorphism (Fok I) and bone mineral density in premenopausal American black and white women. F Bone Miner Res 1997; 12:1043-8.

4 Cooper GS, Umbach DM. Are vitamin D receptor polymorphisms associated with bone mineral density? A meta-analysis. F Bone Miner Res 1996;11:1841-9.

5 Gunnes M, Berg JP, Halse J, Lehmann EH. Lack of relationship between vitamin $\mathrm{D}$ receptor genotype and forearm bone gain in healthy children, adolescents, and forearm bone gain in healthy children, adolescents,

6 Sainz J, Tornout JMV, Loro ML, Sayre J, Roe TF, Gilsanz V. Sainz J, Tornout JMV, Loro ML, Sayre J, Roe TF, Gilsanz V.
Vitamin D receptor gene polymorphisms and bone density in prepubertal American girls of Mexican descent. $N$ Engl 7 Med 1997;337:77-82.

7 Lu PW, Cowell CT, Lloyd-Jones SA, Briody JN, HowmanGiles R. Volumetric bone mineral density in normal subjects, aged 5-27 years. F Clin Endocrinol Metab 1996;81: 1586-90.

8 Lu PW, Briody JN, Ogle GD, et al. Bone mineral density of total body, spine, and femoral neck in children and young adults: a cross-sectional and longitudinal study. F Bone Miner Res 1994;9:1451-8.

9 Keen RW, Egger P, Fall C, et al. Polymorphisms of the vitamin D receptor, infant growth, and adult bone mass. Calcif Tissue Int 1997;60:233-5.

10 Barger-Lux MJ, Heaney RP, Hayes J, DeLuca HF, Johnson ML, Gong G. Vitamin D receptor gene polymorphism, bone mass, body size, and vitamin D receptor density. Calcif Tissue Int 1995;57:161-2. 
11 Kobayashi S, Inoue Shosoi T, Ouchi Y, Shiraki M, Orimo $\mathrm{H}$. Association of bone mineral density with polymorphism of the estrogen receptor gene. F Bone Miner Res 1996;11: 306-11.

12 Grant SFA, Reid DM, Blacke G, Herd R, Fogelmen I, Ralston SH. Reduced bone density and osteoporosis associated with a polymorphic Sp1 binding site in the collagen type I $\alpha 1$ gene. Nat Genet 1996;14:203-5.

13 Fay RA, Dey PL, Sadie CM, Buhl JA, Gebski VJ. Ponderal index: a better definition of the "at risk" group with intrauterine growth problems than birth-weight for gestational age in term infants. Aust NZ $\mathcal{f}$ Obstet Gynaecol 1991;31:17-19.

14 Hamill PVV, Drizd TA, Johnson CL, Reed RB, Roche AF, Moore WM. Physical growth: national center for health statistics percentiles. Am 7 Clin Nutr 1979;32:607-29.

15 Yaich L, Dupont WD, Cavener DR, Parl FF. Analysis of the PvuII restriction fragment-length polymorphism and exon structure of the estrogen receptor gene in breast cancer and structure of the estrogen receptor gene in breast
peripheral blood. Cancer Res 1992;52:77-83.

16 Riggs BL, Nguyen TV, Melton LJ III, et al. The contribution of vitamin D receptor gene alleles to the determination of bone mineral density in normal and osteoporotic women. $f$ Bone Miner Res 1995;10:991-6.

17 Norusis MJ. SPSS version 6.1 Guide to data analysis. Englewood Cliffs, New Jersey: Prentice Hall.

18 Ferrari S, Rizzoli R, Chevally T, Slosman D, Eisman JA Bonjour JP. Vitamin D receptor gene polymorphisms and change in lumbar-spine bone mineral density. Lancet 1995 345:423-4.

19 Gilsanz V, Kovanlikaya A, Costin G, Roe TF, Sayre J, Kaufman F. Differential effect of gender on the sizes of the bones in the axial and appendicular skeletons. 7 Clin Endocrinol Metab 1997;82:1603-7.

20 Nakamura T. The importance of genetic and nutritional factors in responses to vitamin D and its analogs in osteoporotic patients. Calcif Tissue Int 1997;60:119-23.

21 Wishart JM, Horowitz M, Need AG, et al. Relations between calcium intake, calcitriol, polymorphisms of the vitamin D calcium intake, calcitriol, polymorphisms of the vitamin receptor gene, and calcium absorption in

22 Need AG, Horowitz M, Stiliano A, Scopacasa F, Morris HA, Chatterton BE. Vitamin D receptor genotypes are related to bone size and bone density in men. Eur f Clin Invest 1996;26:793-6.

23 Viitanen A-M, Karkkainen M, Laitinen K, et al. Common polymorphism of the vitamin $\mathrm{D}$ receptor gene is associated with variation of peak bone mass in young Finns. Calcif Tissue Int 1996;59:231-4.

24 Spotila LD, Caminis J, Johnston R, et al. Vitamin D receptor genotype is not associated with bone mineral density in three ethnic/regional groups. Calcif Tissue Int 1996;59:235-7.

25 Francis RM, Harrington F, Turner E, Papiha SS, Datta HK. Vitamin D receptor gene polymorphism in men and its effect on bone density and calcium absorption. Clin Endocrinol 1997;46:83-6.

26 Suarez F, Zeghoud F, Rossignol C, Walrant O, Garabedian $M$. Association between vitamin D receptor gene polymorM. Association between vitamin D receptor gene polymor-
phism and sex-dependent growth during the first two years phism and sex-dependent growth during the first two

27 Zofkova I, Kancheva RL, Bendlova B. Effect of 1,25 (OH) vitamin $\mathrm{D}_{3}$ on circulating insulin-like growth factor-I and $\mathrm{B}_{2}$ microglobulin in patients with osteoporosis. Calcif Tissue Int 1997;60:236-9.

\section{Commentary}

It is becoming increasing clear that an individual's risk of developing osteoporosis, a degenerative skeletal disease that affects millions of older people throughout the world, is in part determined by differences in peak bone mass, which is largely achieved by 20 years of age. ${ }^{12}$ Cross sectional twin and family studies suggest that genetic factors account for up to $80 \%$ of the variation in bone mass between individuals, whereas environmental factors such as adequate nutrition (calcium, phosphorus, protein, vitamin $\mathrm{D}$ ) and physical activity influence the extent to which individuals achieve their genetic potential for peak bone mass. ${ }^{3}$ The inheritance of peak bone mass is likely to be under polygenic control, mediated through genes that influence bone mass acquisition during growth. Recent studies have examined associations between polymorphisms in and around a number of candidate genes that are likely to play a role in normal bone homeostasis and the "phenotype" of bone mineral density (BMD). The gene coding for the 1,25-dihydroxyvitamin D receptor (VDR) has been the most extensively studied.
In 1994 Morrison and co-workers ${ }^{4}$ were the first to report an association between BMD and restriction fragment length polymorphism in the VDR gene, defined by the Bsm I restriction endonuclease, in perimenopausal women. Individuals who were homozygous for the VDR allele lacking the Bsm I restriction site (BB genotype) had lower BMD at the spine and femoral neck than those who were homozygous for the allele having the Bsm I site (bb genotype). Morrison et al claimed that the allelic variation in the VDR gene accounted for up to $75 \%$ of heritable variability in bone mass. However, subsequent studies have yielded divergent results with some confirming this association while others have found no association, or the opposite effect. These conflicting results might be due to age or ethnic differences in the expression of the VDR gene effect on BMD, or interactions between the VDR gene and environmental factors (nutrition and physical activity). Some of the other candidate genes studied include the genes for oestrogen receptor, interleukin 6 , insulin-like growth factor 1 , type 1 collagen, and $\alpha_{2} \mathrm{HS}$ glycoprotein.

Tao et al examined associations among polymorphisms in genes for VDR (defined by Bsm I, Taq I, and Fok I endonucleases), oestrogen receptor, and collagen $\mathrm{I} \alpha 1$ and $\mathrm{BMD}$ in healthy, 7 year old, Australian children. BMD was estimated using dual energy $x$ ray absorptiometry (DXA), a technique based on a two dimensional projection of a three dimensional structure. Unlike true bone density-defined as the amount of mass or mineral per unit volume of bone tissue $\left(\mathrm{g} / \mathrm{cm}^{3}\right)$ - "areal BMD" measured by DXA is the amount of bone mineral content divided by the projected bone area, and has units of $\mathrm{g} / \mathrm{cm}^{2}$. Areal BMD is confounded by differences in bone size; it tends to underestimate the BMD of small bones and exaggerate the BMD of large bones. Tao et al's study, the effect of bone size differences on areal BMD was minimised by statistically controlling for height and weight variations. They also calculated volumetric BMD at the femoral shaft, femoral neck, and lumbar spine by modelling DXA obtained data (areal BMD and bone width) at these sites as cylinders. In girls, Taq I and Bsm I (data not provided) VDR gene polymorphisms were associated with areal $\mathrm{BMD}$ at nearly all skeletal sites; girls with " $\mathrm{tt}$ " genotype had significantly lower areal BMD than those with the "TT" genotype. However, after adjusting areal BMD for height and weight and calculation of volumetric BMD, the VDR genotype effect persisted only at the lumbar spine. The inference made is that, in girls, VDR genotype has an important effect on statural growth through bone lengthening and volumetric BMD of the spine. In contrast, none of the genotypes studied were associated with areal or volumetric BMD at any of the skeletal sites in boys.

In adults, there is evidence that VDR polymorphism may have a physiological role in bone mass homeostasis by modulating intestinal calcium. ${ }^{6}$ In a recent study, Ferrari et al examined the interaction between Bsm I VDR 
gene polymorphisms and calcium intake in relation to DXA measured BMD accrual in prepubertal Swiss girls, enrolled in a trial of calcium supplements. ${ }^{7}$ They found that girls with the BB genotype had significantly lower $\mathrm{BMD}$ than those with $\mathrm{Bb}$ or bb genotypes. Calcium supplementation resulted in increased $\mathrm{BMD}$ accrual in girls with $\mathrm{Bb}$ and possibly $\mathrm{BB}$ genotypes, whereas those with bb genotype had the highest spontaneous BMD accrual and remained unaffected by the calcium supplements. These data suggest that increasing calcium intake during childhood in individuals with "unfavourable BMD genes" might allow them to achieve a higher peak bone mass.

Mechanical loading of the skeleton during exercise is known to increase BMD. ${ }^{8}$ Thus it is possible that the VDR genotype effect on BMD might be mediated through an indirect effect on individual muscle mass or muscle strength. Alternatively, it might modulate the sensitivity of the skeleton to mechanical loading by muscles. In Tao et al's study, girls with the VDR genotype associated with high lumbar spine volumetric BMD (TT) were almost $4 \mathrm{~kg}$ heavier than those with the genotype associated with low lumbar spine volumetric BMD (tt). If the higher body weight in these girls resulted from increased muscle mass, then their higher BMD could in part be explained by greater mechanical loading of their lumbar spine. It is, therefore, a pity that the authors did not provide data on lean body mass, which is readily obtainable from total body DXA scans, and which would have provided an index of the total amount of muscle in the subjects. The lack of VDR gene effect on height, weight, and BMD in boys is difficult to explain.

In summary, Tao et al's results and a few other paediatric studies ${ }^{79}$ suggest that in girls, certain VDR alleles (such as BB and tt) may be markers of low peak bone mass. If these findings are confirmed, they may allow identification of girls who are at a higher risk of developing early osteoporosis. Targeting of intervention strategies for increasing BMD, such as exercise and calcium supplements might help these individuals attain a higher peak bone mass. Short term studies indicate that such interventions have greater effects on BMD before puberty, ${ }^{8}{ }^{10}$ suggesting that prevention of osteoporosis should be started during early childhood. Randomised controlled intervention studies, with follow up of children through to adulthood are needed to determine whether peak bone mass can actually be increased through such health education programmes.

ZULF MUGHAL

Paediatric Metabolic Bone Diseases Clinic, St Mary's Hospital for Women E Children, Hathersage Road, Manchester M13 OfH, UK

email:MMUGHAL@fs1.cmht.nwest.nhs.uk

1 Bonjour JP, Theintz G, Buchs B, Slosman D, Rizzoli R. Critical years and stages of puberty for spinal and femoral bone mass accumulation during adolescence. 7 Clin Endocrinol Metab 1991;73:555-63.

2 Matkovic V, Jelic T, Wadlaw GM, et al. Timing of peak bone mass in caucasian females and its implications for the prevention of osteoporosis. $\mathcal{F}$ Clin Invest 1994;93:79-808.

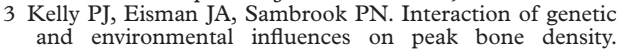
Osteoporos Int 1990;1:56-60.

4 Morrison NA, Qi JC, Tokita A, et al. Prediction of bone density from vitamin D receptor alleles. Nature 1994;367: 284-7.

5 Greenfield EM, Goldberg VM. Genetic determination of bone density. Lancet 1997;350:1263-4.

6 Dawson-Hughes B, Harris SS, Finneran S. Calcium absorption on high and low calcium intakes in relation to absorption on high and low calcium intakes in relation to
vitamin D receptor genotype. F Clin Endocrinol Metab vitamin D recept

7 Ferrari SL, Rizzoli R, Slosman DO, Bonjour JP. Do dietary calcium and age explain the controversy surrounding the relationship between bone mineral density and vitamin D receptor gene polymorphisms? F Bone Miner Res 1998;13: 363-70.

8 Bass S, Pearce G, Bradney M, et al. Exercise before puberty may confer residual benefits in bone density in adulthood: studies in active prepubertal and retired female gymnasts. $\mathcal{F}$ Bone Miner Res 1998;13:500-7.

9 Sainz J, Van Tornout JM, Loro ML, Sayre J, Roe TF, Gilsanz V. Vitamin D-receptor gene polymorphisms and bone density in prepubertal American girls of Mexican descent. N Engl f Med 1997;337:77-82.

10 Johnston CC Jr, Miller JZ, Slemenda CW, et al. Calcium supplementation and increases in bone mineral density in supplementation and increases in bone
children. N Engl f Med 1992;327:82-7. 